\title{
BAURAN PEMASARAN PRODUK BARU PELUMAS FOOD GRADE GREASE BERBAHAN DASAR MINYAK SAWIT
}

\author{
Ali Maksum dan Tri Yanto \\ Teknologi Pertanian Universitas Jenderal Soedirman \\ Alamat email: alimaksum40@gmail.com
}

\begin{abstract}
Grease with food grade specification is essentially required on food processing production activities. The purpose of this study is to develop a new product marketing mix for food grade grease, i.e 1) product priority, 2) pricing priority, 3) distribution priority and 4) advertising priority. This Research was conducted in Sub District Purbalingga and Padamara, Purbalingga regency with respondent SMEs food processing. Analysis of the determination of marketing mix that includes product, price, advertising and distribution using the Analytical Hierarchy Process (AHP). Sampling was purposive random sampling method with a population of 64 SMEs so drawn sample of 20 respondents. Result of the study showed the marketing mix priority which were: (1) advertising priority for the new food grade grease product with an ads that could attract the attention of consumers in order to made the consumers interested, tried, and bought the new food grade lubricating grease products. (2) Price priority for the new food grade grease products which was by determining the moderate prices to compete the competitors' prices while still maintained a high quality. (3) Product priority for new food grade grease product which was producing a qualified product which could withstand the wear of the engine, green colour of the product, a $350 \mathrm{~g}$ size packs with a rectangular shape packaging labels. (4) Distribution priority for the new food grade grease product which was a short distribution channels through mobile vendors so that the consumers were able to save costs, and got the product fast and easily.
\end{abstract}

Key words: new product, food grade grease, marketing mix, AHP.

\section{PENDAHULUAN}

Perkembangan industri pengolahan pangan di Indonesia terus meningkat. Berdasarkan data dari Badan Pusat Statistik (2011), industri pengolahan Indonesia mengalami peningkatan dari tahun 2005-2008 dari 20.729 menjadi 25.694 unit usaha. Pada tahun 2010 pertumbuhan industri pengolahan naik $1,34 \%$.

Peningkatan industri pengolahan berbanding lurus dengan peningkatan penggunaan mesin untuk kegiatan produksi. Mesin membutuhkan perawatan yang baik agar mesin menghasilkan ouput yang optimal. Salah satu perawatan mesin tersebut adalah penggunaan pelumas baik berupa pelumas cair maupun pelumas padat.
Pelumas padat yang digunakan khusus untuk mesin industri pengolahan pangan mengunakan pelumas food grade grease (FGG). FGG adalah grease yang berbahan dasar minyak nabati yang baik digunakan sebagai pelumasan khususnya untuk industri pangan (Yanto et al., 2006; Sukirno et al., 2009). Akan tetapi, belum semua industri pengolahan pangan menggunakan FGG sebagai pelumas mesin pengolahan pangan khususnya untuk Industri Kecil Menengah (IKM). IKM pengolahan pangan di Kabupaten Purbalingga belum menggunakan pelumas FGG, mereka menggunakan pelumas non-food grade grease (NFGG)yang berbahan dasar dari mineral. 
Bahaya penggunaan pelumas NFGG jika mengkontaminasi hasil olahan dan dikonsumsi manusia adalah terjadinya penimbunan bahan anorganik khususnya logam berat yang dapat mengakibatkan keracunan pada konsumen yang berdampak pada kesehatan (Kupcinskas et al., 2012).

Alasan IKM pengolahan pangan menggunakan pelumas NFGG karena pelumas mesin yang tersedia dipasaran adalah NFGG. Pelumas yang diinginkan IKM pengolahan pangan yaitu harganya terjangkau, mudah mendapatkannya, kualitas yang bagus dan tidak mudah mencair.

Pelumas FGG berbahan dasar minyak sawit telah memenuhi keinginan IKM pengolahan pangan yaitu tidak mudah mencair dengan titik leleh $190,5^{\circ} \mathrm{C}$, daya lekat pelumas pada mesin yang bagus dengan nilai kebocoran pada wheel bearing 25,56 g, melindungi mesin dari korosi dengan daya tahan korosi 1a. Dengan spesifikasi tersebut pelumas FGG berbahan dasar minyak sawit dapat melindungi mesin dari keausan sehingga mesin tetap awet (Yanto et al. 2009).

Kebutuhan pelumas IKM pengolahan pangan di Kabupaten Purbalingga pada tahun 2012 mencapai 329.145,6 kg/tahun. Pada tahun 2021 diprediksi permintaan FGG mencapai 393.359,4 $\mathrm{kg} /$ tahun (Yanto et al.,2012). Permintaan FGG yang mencapai 393.359,4 kg/tahun pada tahun 2021, sampai saat ini belum ada industri kecil yang mencoba untuk memenuhi permintaan tersebut dikarenakan belum adanya informasi terkait produk pelumas FGG baik dari segi spesifikasi produk, harga, lokasi dan promosi yang diinginkan konsumen.

Guna memenuhi kebutuhan informasi konsumen tersebut diperlukan bauran pemasaran pada produk baru pelumas FGG. Bauran pemasaran merupakan kumpulan alat pemasaran taktis terkendali terdiri dari produk, harga, tempat, dan promosi yang dipadukan perusahaan untuk menghasilkan respons yang diinginkan di pasar sasaran (Kotler dan Amstrong, 2008).

Pertimbangan konsumen termasuk didalamnya IKM dalam pengambilan keputusan pembelian suatu produk dipengaruhi oleh informasi yang mereka terima, termasuk diantaranya unsur-unsur bauran pemasaran. Bauran pemasaran produk yang direspon positif oleh konsumen akan memiliki peluang yang besar bagi produk tersebut untuk dibeli. Dapat diasumsikan bahwa penilaian atau tanggapan konsumen terhadap bauran pemasaran akan mempengaruhi keputusan pembelian konsumen.

FGG merupakan produk pelumas baru yang belum diketahui oleh IKM pegolahan pangan di Kabupaten Purbalingga sehingga diperlukan penentuan prioritas strategi bauran pemasaran produk baru FGG untuk menunjang keberhasilan produksi pelumas FGG. Tujuan penelitian ini adalah untuk: 1) menentukan prioritas produk untuk produk baru FGG; 2) menentukan prioritas harga untuk produk baru FGG; 3) menentukan prioritas distribusi untuk produk baru FGG; 4) menentukan prioritas promosi untuk produk baru FGG. Penelitian ini diharapkan memberikan manfaat yaitu: 1) membantu memberikan masukan kepada produsen dalam menentukan prioritas strategi bauran pemasaran yang tepat sehingga mendapatkan keuntungan yang optimal; 2) menambah informasi yang dapat digunakan untuk pengembangan penelitian mengenai strategi bauran pemasaran.

\section{METODOLOGI}

Objek yang diteliti pada penelitian ini adalah prioritas bauran pemasaran produk baru pelumas FGG. Sasaran penelitian ini adalah industri pengolahan pangan di Kabupaten Purbalingga yang diwakili Kecamatan Purbalingga dan Kecamatan Padamara. Jenis penelitian ini adalah penelitian kebijakan dengan metode Purposive berdasarkan geografis untuk mentukan lokasi penelitian, penentuan sampel dengan metode simple random sampling pada pelaku industri pengolahan pangan.

Tahapan penelitian ini diselaraskan dengan langkah-langkah Analytical Hierarchy Process (AHP) sebagai berikut:

1. Decomposition.

a. Mendefinisikan permasalahan dan merinci pemecahan permasalahan strategi bauran pemasaran produk baru pelumas FGG yang diinginkan. 
b. Membuat struktur hirarki dari sudut pandang produk baru pelumas FGG secara menyeluruh.

2. Comparative Judgement

a. Membuat matrik perbandingan berdasarkan struktur hirarki produk baru pelumas FGG secara menyeluruh.

b. Penentuan sampel (responden)

Pengambilan sampel menggunakan teknik purposive random sampling. Purposive berdasarkan pada geografis. Geografis yang dimaksud adalah lokasi daerah yang berada di pusat kota dan daerah yang berada di pinggiran kota. Berdasarkan pertimbangan tersebut dipilih Kecamatan Purbalingga mewakili lokasi pusat kota dan Kecamatan Padamara mewakili lokasi pinggir kota. Populasi yang ditunjuk adalah IKM pengolahan pangan yang terdapat di Kecamatan Padamara dan Kecamatan Purbalingga Kabupaten Purbalingga. Jumlah populasi industri pengolahan pangan di Kecamatan Purbalingga dan Kecamatan Padamara sebesar 64 buah. Banyaknya responden (konsumen) yang diwawancarai sebanayak 30\% dari total populasi (Gay dan Diehl, 1992). Jadi total sampel yang diambil sebanyak 20 responden.

c. Membuat matrik pendapat individu

d. Mengumpulkan semua pertimbangan yang dilakukan dari hasil perbandingan.

e. Memasukkan nilai kebalikan beserta bilangan sepanjang diagonal utama.

f. Membuat matrik pendapat gabungan.

3. Synthesis of Priority

Perhitungan Vektor Prioritas (VP) atau rasio Vektor Eigen adalah:

$$
V P i=\frac{\sqrt[n]{\prod_{k=1}^{n} a i j}}{\sum_{k=1}^{n} \sqrt[n]{\prod_{k=1}^{n} a i j}}
$$

$\mathrm{VP}=(\mathrm{Vpi})$, untuk $\mathrm{i}=1,2,3, . . \mathrm{n}$

\section{Logical Consistency}

Perhitungan rasio Inkonsistensi (CR), dengan rumus:

$$
C R=\frac{C I}{R I}
$$

$\mathrm{RI}=$ indeks acak (random indeks) menurut Saaty dari matrik berorde 1s/d 15 menggunakan sampel berukuran 100 .

\section{HASIL DAN PEMBAHASAN}

\section{Prioritas Elemen Bauran Pemasaran}

Elemen bauran pemasaran merupakan hirarki pada tingkat kedua, untuk mengetahui elemen bauran pemasaran yang diprioritaskan dalam strategi bauran pemasaran produk baru pelumas FGG disajikan pada Gambar 1.

Elemen promosi menjadi prioritas pertama dalam bauran pemasaran produk baru pelumas FGG dengan bobot 0,303. Promosi menempati prioritas utama dikarenakan konsumen belum mengetahui produk baru pelumas FGG. Mereka hanya mengetahui grease berbahan dasar mineral dan sintetik yang banyak beredar di pasaran. Ketidaktauan konsumen terhadap FGG dikarenakan tidak adanya grease yang berspesifikasi food grade yang beredar di pasaran terutama di wilayah Kabupaten Purbalingga. Konsumen yang tidak mengetahui informasi produk FGG tidak akan mencari produk tersebut apalagi membeli produk sehingga promosi menempati prioritas utama dibandingkan harga, produk, dan distribusi.

Promosi merupakan faktor yang penting dalam menginformasikan keberadaan dan keunggulan pelumas FGG. FGG yang berbahan dasar minyak sawit merupakan pelumas baru yang belum dikenal oleh calon konsumen, sehingga dibutuhkan promosi yang tepat agar pelumas tersebut dapat diketahui keberadaan dan keunggulannya. Promosi bertujuan untuk menginformasikan, mempengaruhi, membujuk dan mengingatkan konsumen tentang produk atau jasa yang akan ditawarkan perusahaan, sehingga akan timbul permintaan (Kotler, 1997; Firdaus, 2011). 


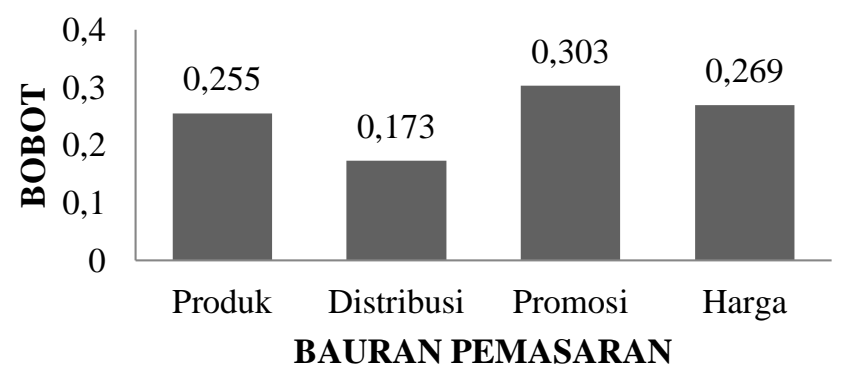

Gambar 1. Prioritas elemen bauran pemasaran

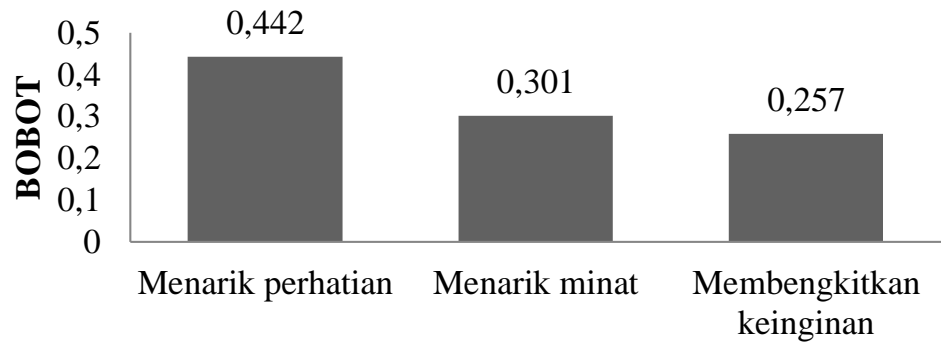

FAKTOR PROMOSI

Gambar 2. Prioritas faktor elemen promosi

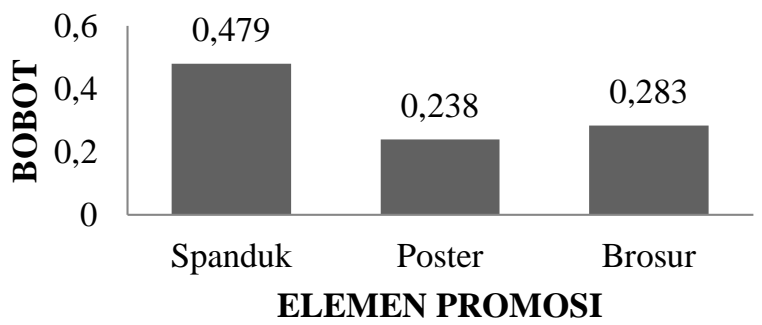

Gambar 3. Prioritas alternatif elemen promosi

\section{Prioritas Elemen Promosi}

Elemen promosi disusun berdasarkan atas prioritas faktor elemen promosi dan alternatif elemen promosi.

1. Prioritas faktor elemen promosi

Prioritas faktor elemen promosi produk baru pelumas FGG disajikan pada Gambar 2. FGG sebagai produk baru yang belum diketahui oleh konsumen harus melakukan promosi yang tepat agar produk FGG diketahui konsumen. Penentuan Faktor promosi merujuk pada pendapat Puspitasari (2009) meliputi menarik perhatian, menarik minat dan membangkitkan keinginan. Faktor promosi yang diprioritaskan responden adalah promosi yang menarik perhatian, dibandingkan faktor menarik minat dan membangkitkan keinginan. Konsumen menginginkan promosi yang menarik perhatian karena dengan promosi yang menarik perhatian, mereka lebih memperhatikan informasi yang terdapat dalam media promosi tersebut. FGG sebagai produk baru diperlukan promosi yang menarik perhatian agar calon konsumen ingin mencoba karena tertarik dengan promosi yang dilakukan. Dengan promosi yang menarik perhatian juga diharapkan dapat membuat konsumen berminat ingin mencoba dan membeli produk baru pelumas FGG.

2. Prioritas alternatif elemen promosi

Prioritas alternatif elemen promosi produk baru pelumas FGG tersaji pada Gambar 3. 


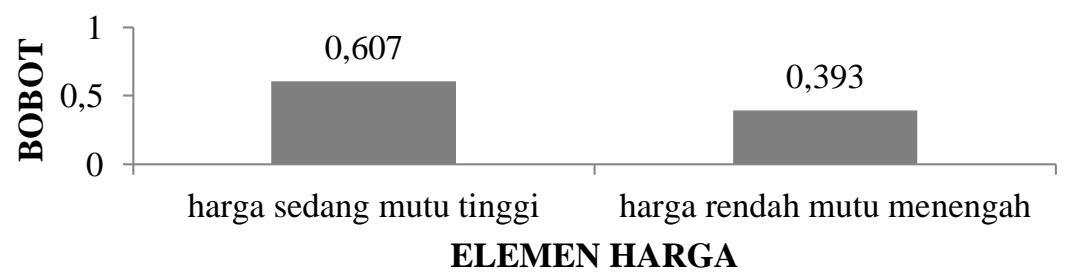

Gambar 4. Prioritas alternatif elemen harga

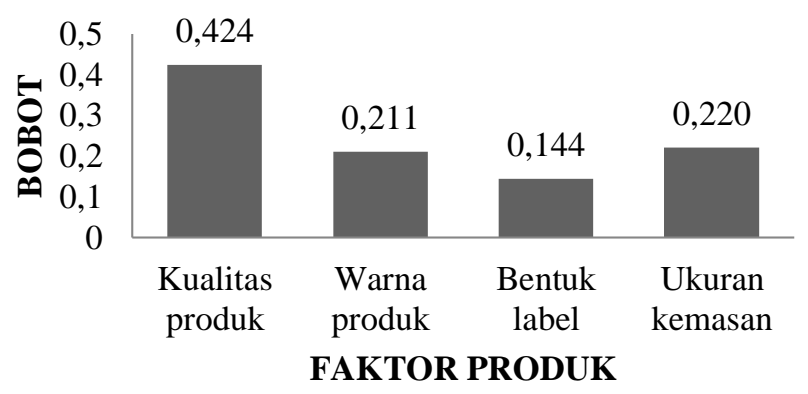

Gambar 5. Prioritas faktor elemen produk

Penentuan alternatif elemen promosi berupa spanduk, poster dan brosur di peroleh dari survei dan observasi lapang. Spanduk menempati prioritas pertama dikarenakan spanduk merupakan alat promosi yang paling menarik perhatian, menarik minat dan membangkitkan keinginan. Spanduk mempunyai keunggulan yaitu khalayak dapat mengatur tempo dalam membaca. Ia dapat mengulang bacaannya kembali dan mengatur cara membaca. Media yang dapat dibaca pembaca dengan tenang, teliti dan dibaca kembali bagian-bagian menurut kehendaknya.

\section{Prioritas Elemen Harga}

Elemen harga disusun berdasarkan prioritas alternatif elemen harga produk baru pelumas FGG yang disajikan pada Gambar 4. Elemen harga terdiri dari harga sedang mutu tinggi dan harga rendah mutu menengah berdasarkan strategi hubungan harga dengan mutu (Kotler, 2005). Pelumas FGG agar mampu bersaing dengan produk pelumas lain yang telah mapan dipasaran harus mampu bersaing dalam hal harga dan kualitas. Harga sedang menjadi pilihan konsumen dikarenakan meninjau harga pelumas FGG dipasaran yang lebih mahal dibandingkan harga pelumas NFGG sehingga diharapkan ada produk baru pelumas grease yang berspesifikasi food grade yang harganya mampu bersaing dengan pelumas NFGG yang ada di pasaran.

Pemilihan harga sedang mutu tinggi untuk produk baru FGG ini sesuai dengan pendapat Tellis (1986) yang menyatakan bahwa, produk baru dalam memasuki pasar baru menggunakan strategi penetration price yaitu strategi dengan menetapkan harga rendah pada awal produksi, dengan tujuan dapat meraih pangsa pasar yang besar dan sekaligus menghalangi masuknya para pesaing. Stratergi penetration price ditetapkan atas suatu produk baru dapat memberikan pengaruh yang baik bagi petumbuhan pasar dan mencegah timbulnya persaingan yang sengit (Tjiptono 2002).

\section{Prioritas Elemen Produk}

Elemen promosi disusun berdasarkan atas prioritas faktor elemen produk dan alternatif elemen produk.

1. Prioritas faktor elemen produk

Prioritas faktor elemen promosi produk baru pelumas FGG disajikan pada 
Gambar 5. Faktor kualitas produk menempati prioritas pertama dari elemen produk dalam strategi pemasaran produk baru pelumas FGG dari responden dengan bobot 0,424 karena konsumen menginginkan grease yang mampu melindungi mesin mereka dari keausan sehingga mesin mampu bekerja secara optimal. Konsumen membeli grease dengan tujuan utama agar mesin mereka awet, untuk tujuan tersebut maka mereka membeli grease yang berkualitas. Mesin yang awet akan mengurangi biaya perawatan mesin sehingga biaya yang diukeluarkan untuk perawatan mesin dapat dikurangi. Tujuan utama membeli grease untuk keawetan mesin menempatkan kualitas produk diatas ukuran kemasan, warna produk dan bentuk label.

Produk FGG yang berkualitas mampu bersaing dengan kompetitor pelumas yang lain. Produk pelumas yang berkualitas mampu memenuhi harapan konsumen yaitu melindungi mesin dan alat pengolahan pangan dengan optimal sehingga mesin menjadi awet. Kualitas produk merupakan faktor yang menentukan kepuasan konsumen agar konsumen tetap loyal terhadap produk pelumas FGG sehingga produk pelumas FGG tetap laku dan mampu bersaing dengan produk sejenis dipasaran (Marimin dan Muspitawati, 2002).

2. Prioritas elemen alternatif produk

a. prioritas alternatif elemen faktor kualitas produk
Prioritas alternatif elemen faktor kulaitas produk baru pelumas FGG disajikan pada Gambar 6.

Mencegah aus menempati prioritas pertama dari alternatif kualitas produk menunjukkan bahwa konsumen menginginkan produk yang mampu melindungi mesin dari keausan. Jika mesin mengalami keausan maka kinerja mesin akan menurun dan nilai ekonomis mesin turun sehingga mesin menjadi tidak awet dan menghasilkan produk yang tidak optimal.

Pelumas yang mampu mencegah aus ditunjukkan dengan nilai uji four ball mencakup pemeriksaan sifat penahanan tekanan sangat tinggi (extreme pressure). Pengujian four ball meliputi dua macam pengujian, yaitu welding point (titik pengelasan) dan uji wear. FGG minyak sawit memiliki nilai welding point $200 \mathrm{Kg}$. Hal tersebut menunjukkan bahwa tingkat kemampuan grease untuk menahan tekanan ekstrim adalah $200 \mathrm{Kg}$. Tekanan beban maksimal pada $200 \mathrm{Kg}$ menunjukkan kemampuan grease uji menahan tekanan ekstrim telah terlampaui dan selanjutnya grease tidak mampu melumasi (Yanto, 2010).

b. Prioritas alternatif elemen faktor warna produk

Hasil pengolahan prioritas elemen alternatif faktor warna produk baru pelumas FGG disajikan pada Gambar 7.

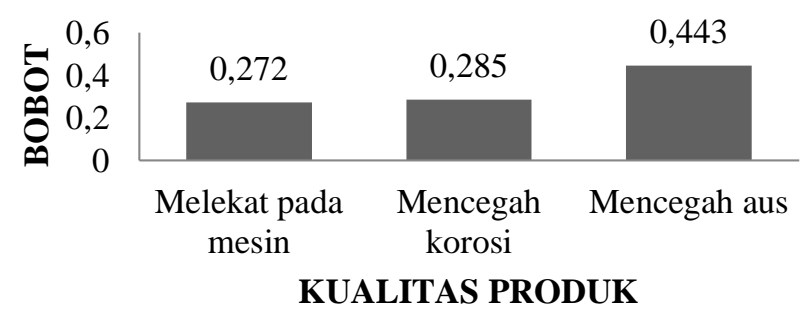

Gambar 6. Prioritas alternatif elemen kualitas produk

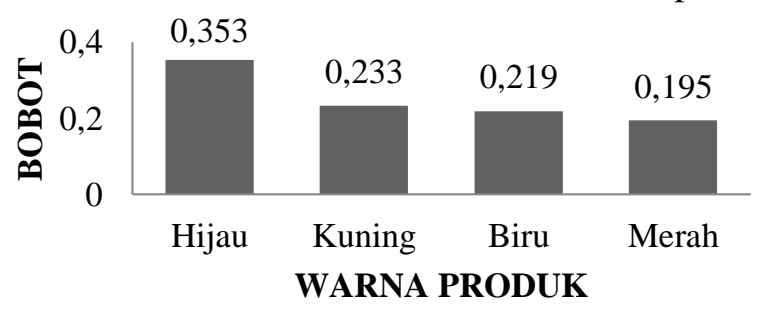

Gambar 7. Prioritas alternatif elemen warna produk 
Warna hijau menempati prioritas pertama yang dipilih oleh konsumen pelumas karena warna hijau memiliki efek yang menenangkan. Berdasarkan Marc Gobe (2005), warna hijau merupakan warna yang mempunyai gelombang pendek yang memberikan kesan warna yang sejuk dan alami. Kesan ini yang memberikan efek ke produk pelumas FGG bahwa produk ini merupakan produk yang ramah lingkungan dan tidak menimbulkan dampak kesehatan karena tebuat dari bahan dasar minyak nabati yang mudah terurai.

c. Prioritas alternatif elemen faktor bentuk label produk

Prioritas alternatif elemen faktor bentuk label produk baru pelumas FGG disajikan pada Gambar 8.

Bentuk label persegi panjang menempati prioritas pertama karena label persegi panjang menempel pada bagian tubuh kemasan dibandingkan bentuk label lingkaran yang menempel pada tutup kemasan. Label yang terpasang ditutup kemasan berdasarkan penilaian dari konsumen menyatakan bahwa label tersebut dikhawatirkan hilang karena tutup kemasan mudah sekali hilang sehingga label bentuk kemasan tidak menjadi prioritas utama. Peranan label pada suatu produk sangat penting untuk memperoleh produk yang sesuai dengan yang diinginkan konsumen.

Label produk yang dijamin kebenarannya aka $\mathrm{n}$ memudahkan konsumen dalam menentukan beragam produk dan subtitusi di pasaran serta label juga dapat memberikan nilai tambah bagi produk (Engel et al., 1995).

d. Prioritas alternatif elemen faktor ukuran kemasan produk

Prioritas alternatif elemen faktor ukuran kemasam produk baru pelumas FGG disajikan pada Gambar 9.

Ukuran kemasan $350 \mathrm{~g}$ menempati prioritas pertama karena kebutuhan IKM pengolahan pangan sebagai konsumen FGG setiap bulan mencapai $250 \mathrm{~g}-400 \mathrm{~g} /$ bulan, sehingga konsumen memilih grease dengan volume atau isi yang sesuai dengan kebutuhan mereka. Hal ini sesuai dengan hasil penelitian Putri (2012), bahwa konsumen lebih menyukai grease dengan ukuran kemasan $350 \mathrm{~g}$ yang disebabkan oleh tingkat kebutuhan dalam pemakaian grease. Ditinjau dari segi kepraktisan, ukuran kemasan $350 \mathrm{~g}$ lebih praktis dalam penyimpanan dibandingkan ukuran kemasan yang lain.

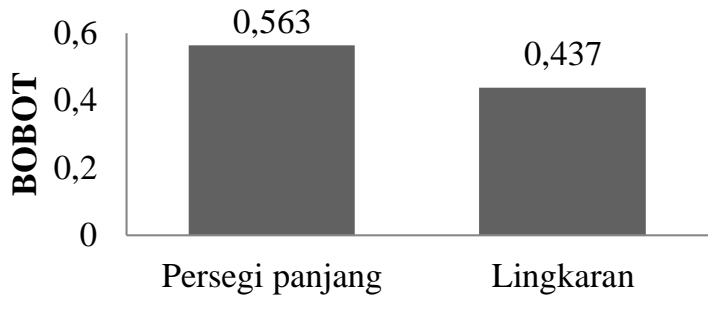

BENTUK LABEL PRODUK

Gambar 8. Prioritas alternatif elemen bentuk label produk

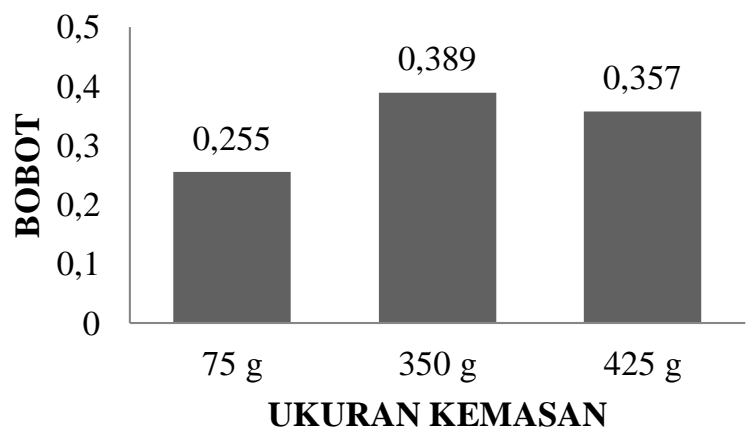

Gambar 9. Prioritas alternatif elemen ukuran kemasan produk 


\section{Prioritas Elemen Distribusi}

Elemen promosi disusun berdasarkan atas prioritas faktor elemen produk dan alternatif elemen produk.

1. Prioritas faktor elemen distribusi

Prioritas faktor elemen promosi produk baru pelumas FGG disajikan pada Gambar 10. Faktor distribusi yang menempati prioritas pertama dengan bobot 0,305 adalah faktor biaya untuk memperoleh produk. Konsumen memprioritaskan faktor ini karena mereka tidak ingin mengeluarkan biaya yang lebih besar lagi untuk mendapatkan produk, dimana semakin besar pengeluaran biaya yang mereka keluarkan akan menambah beban biaya pengeluaran sehingga akan menurunkan pendapatan. Mereka menginginkan biaya yang dikeluarkan untuk mendapatkan produk sekecil mungkin.

Distribusi yang akan dipilih untuk strategi pemasaran produk baru FGG harus memperhatikan biaya tambahan dari konsumen dalam mendapatkan produk. Sebagaimana laporan Bank Indonesia Ambon (2011), konsumen cenderung memperhatikan biaya untuk memperoleh produk, sehingga lebih menyukai rantai saluran distribusi pendek. Konsekuensi saluran distribusi pendek adalah biaya distribusi yang ditanggung oleh produsen semakin tinggi (Suwarno, 2006).

2. Prioritas alternatif elemen distribusi

Prioritas alternatif elemen distribusi dapat diketahui prioritas utama untuk alternatif distribusi produk baru pelumas FGG tersaji pada Gambar 11. Secara keseluruhan hasil analisis prioritas elemen alternatif distribusi, penjual keliling menempati prioritas pertama dikarenakan dengan distribusi menggunakan penjual keliling konsumen mampu menghemat biaya untuk mendapatkan pelumas, lebih mudah dan cepat mendapatkan produk karena jalur distribusi yang pendek sehingga produsen langsung bertemu dengan konsumen. Biaya, kemudahan dan kecepatan mendapatkan produk menjadi kunci distribusi yang baik agar produk mampu diakses oleh konsumen sehingga meningkatkan kepuasan pelanggan dengan harapan konsumen loyal terhadap produk yang dipasarkan.

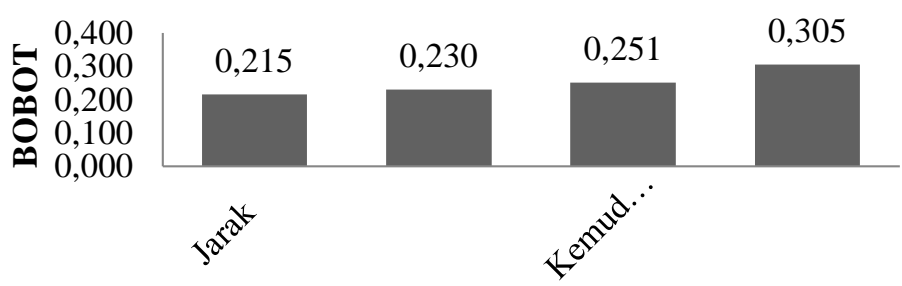

FAKTOR DISTRIBUSI

Gambar 10. Prioritas faktor elemen distribusi

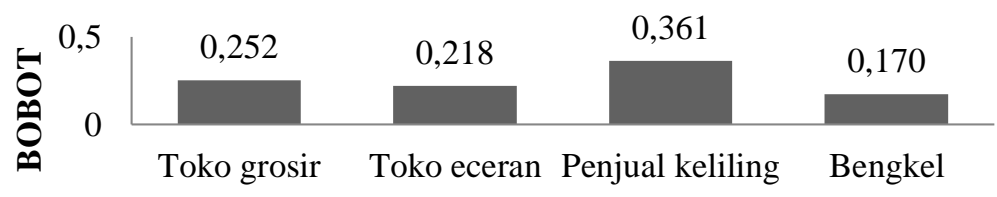

ELEMEN DISTRIBUSI

Gambar 11. Prioritas alternatif elemen warna produk 


\section{KESIMPULAN DAN SARAN}

\section{Kesimpulan}

Prioritas promosi untuk produk baru FGG yaitu dengan membuat iklan yang dapat menarik perhatian konsumen sehingga dapat membuat konsumen berminat ingin mencoba dan membeli produk baru pelumas FGG. Prioritas harga untuk produk baru FGG yaitu dengan menentukan harga sedang yang mampu bersaing dengan harga kompetitor dengan tetap enjaga kualitas yang tinggi. Prioritas produk untuk produk baru FGG yaitu dengan memproduksi produk berkualitas yang mampu menahan aus pada mesin, warna produk hijau, ukuran kemasan $350 \mathrm{~g}$ dengan bentuk label kemasan persegi panjang. Prioritas distribusi untuk produk baru FGG yaitu dengan jalur distribusi pendek melalui pedagang keliling sehingga konsumen mampu menghemat biaya, mudah dan cepat mendapatkan produk.

\section{Saran}

Pengembangan sistem promosi yang lebih variatif seperti sales promotion dan sponsorship marketing sehingga konsumen lebih mengenal dan tertarik terhadap produk baru pelumas FGG. Dilakukan strategi penetapan harga yang tepat yang sesuai prioritas konsumen yaitu harga menengah mutu tinggi sehingga produsen yang akan memproduksi FGG tidak mengalami kerugian bahkan mampu bersaing dengan grease yang sudah mapan di pasaran. Dilakukan pengembangan penelitian strategi bauran pemasaran produk baru pelumas FGG tidak hanya terbatas pada produk, harga, distribusi dan promosi, misalkan costumer service.

\section{DAFTAR PUSTAKA}

Bank Indonesia Ambon. 2011. Kajian Harga Dan Implikasinya Pada Rantai Distribusi. Kajian Ekonomi Regional Provinsi Maluku Triwulan I. Ambon.

Badan Pusat Statistik. 2011. Daftar Industri Pengolahan Indonesia. http://www.bps.go.id. [15 Mei 2012].

Engel JF, Blackwell RD dan Miniard PW. 1995. Perilaku Konsumen jilid 1 ( $6^{\text {th }}$ ed.). Jakarta: Binarupa Aksara.

Firdaus Y. 2011. Peranan Biaya Promosi Dalam Meningkatkan Volume
Penjualan (Studi Kasus Pada Salah Satu Perusahaan Pembiayaan di Palembang). Jurnal Ekonomi dan Informasi Akuntansi (JENIUSI). 1: 143-152.

Gay LR dan Diehl PL. 1992. Research Methods for Business and Management. New York: MacMillan Publishing Company.

Gobe' M. 2005. Emotional Branding: Paradigma Baru untuk Menghubungkan Merek dengan Pelanggan. Jakarta: Erlangga.

Kotler P. 1997. Manajemen Pemasaran; Analisis, Perencanaan, Implementasi dan Kontrol. Jakarta: Prenhallindo.

Kotler P. 2005. Manajemen Pemasaran. Jilid 1. Jakarta: PT. Indeks Kelompok Gramedia.

Kotler P dan Armstrong G. 2008. PrinsipPrinsip Pemasaran. Jakarta: Erlangga.

Kupčinskas A, Kreivaitis R, Padgurskas J, Makarevičienè $\mathrm{V}$ and Gumbytė $\mathrm{M}$. 2012. Modification of rapeseed oil and lard by monoglycerides and free fatty acids. Jurnal Mechanika. 18:113-118.

Marimin dan Muspitawati H. 2002. Kajian Strategi Peningkatan Kualitas Produk Industri Sayuran Segar (Studi Kasus Di Sebuah Agroindustri Sayuran Segar). Jurnal Teknologi dan Industrl Pangan. 8: 224-233.

Puspitasari I. 2009. Faktor-Faktor Yang Mempengaruhi Efektifitas Iklan Dalam Menumbuhkan Brand Awareness. Tesis. UNDIP, Semarang.

Putri VA. 2012. Pengaruh Jenis dan Volume Kemasan Terhadap Karakteristik Grease Minyak Jelantah. [Skripsi yang tidak dipunlikasikan, Fakultas Pertanian UNSOED, Purwokerto].

Sukirno., Fajar R, Bismo S and Nasikin M. 2009. Biogrease Based on Palm Oil and Lithium Soap Thickener: Evaluation of Antiwear Property. World Applied Sciences Journal. 6: 401-407.

Suwarno HL. 2006. Sembilan Fungsi Saluran Distribusi: Kunci Pelaksanaan Kegiatan Distribusi Yang Efektif. Jurnal Manajemen. 6: 34-44.

Suyanto M. 2004. Aplikasi Desain Grafis untuk Periklanan. Yogyakarta: Andi Offset. 
Tellis GJ. 1986. Beyond the Many Faces of Price: An Integration of Pricing Strategies. Journal of Marketing. 50: 146-160.

Yanto T, Erminawati dan Masrukhi. 2006. Pemanfaatan Minyak Goreng Bekas Sebagai Bahan Dasar Pelumas Grease Berkualitas. [Laporan yang tidak dipublikasikan Fakultas Pertanian Unsoed, Purwokerto].

Yanto T, Erminawati dan Naufalin R. 2009. Uji kinerja dan Preferensi Konsumen terhadap Food Grade Grease Dengan Bahan Dasar Minyak Sawit. [Laporan yang tidak dipublikasikan Fakultas Pertanian Unsoed, Purwokerto].

Yanto T. 2010. Formulasi Rolling Oil dengan Bahan Dasar Jarak. Malang: Penerbit Malak.

Yanto T, Waluyo SB dan Sulistyo SB. 2012. Profil Teknoekonomiindustri Food Grade Grease Dengan Bahan Dasar Minyak Sawit Skala Home Industri. Prosiding Makalah Seminar Nasional Pengembangan Sumberdaya Pedesaan dan Kearifan Lokal Berkelanjutan II. Purwokerto 27 - 28 November 2012. LPPM Unsoed, Purwokerto. 